\title{
LA Propuesta SaRkariana y EL REDUCCIONISMo GENÉTICO-MOLECULAR
}

\author{
The Sarkarian Proposal and Molecular-genetic Reductionism \\ CHRISTIAN FEDERICO FRANCESE \\ Universidad de Buenos Aires, ARgentinA \\ francese.christian@gmail.com \\ GUILLERMO FOLGUERA \\ Universidad de Buenos Aires / CONICET, ARGENTINA \\ guillefolguera@yahoo.com.ar
}

\begin{abstract}
One of the most interesting and influential proposals on the subject of reductionism in Biology has been presented by Sahotra Sarkar, mainly in his book Genetics and Reductionism. There the author proposes a general model of reduction and uses it to analyze the reductive relationships between genotype and phenotype, and of Biology with Chemistry and Physics. One of his thesis is that both reductionisms are entirely different conceptual approaches with no relation between them. In this article we critically explore the Sarkarian thesis. Here we argue that the two reductionisms are deeply interconnected and that together they shape an extended vision in contemporary Biology as well as fundamental in current biotechnological projects. We have called such perspective "genetic-molecular reductionism" and characterized from the general Sarkar reduction model. The work carried out allows us to expose both the scope of the Sarkarian proposal itself and some remarkable characteristics of a prevalent perspective in Biology.
\end{abstract}

Keywords: reductionism $\bullet$ biology $\bullet$ molecular genetics $\bullet$ Sarkar

\section{Introducción}

Una de las temáticas recurrentes entre quienes se han enfocado en la relación entre distintos ámbitos del conocimiento ha sido la problemática de la reducción. A grandes rasgos, una reducción consiste en que teorías, fenómenos, metodologías o entidades de un dominio científico puedan caracterizarse o ser puestos en términos de teorías, fenómenos, metodologías o entidades de otro dominio de la ciencia. Se presenta así el vínculo entre dos ámbitos del conocimiento: uno que reduce y otro que es reducido. En el caso del vínculo entre áreas de conocimientos de las ciencias naturales, las áreas de saber propias de los niveles inferiores de organización son asignadas a los campos reductores. Desde luego, la propuesta reduccionista apunta a presentar al dominio reductor como ámbito de mayor relevancia para la investigación científica, mientras 
que la posición contraria invalida tal perspectiva (Klimovsky 1997; Bringandt y Love 2017).

En los estudios sobre los seres vivos, durante gran parte del siglo XX fueron consolidándose diferentes tipos de predominios. En paralelo, el advenimiento de técnicas propias de la Química y la Física a la Biología le ha otorgado un enorme prestigio a la disciplina biológica, ya que le ha permitido adquirir capacidad de indagación y manipulación de los niveles inferiores de organización (Keller, 1990). A su vez, el éxito que la aproximación molecular ha tenido en sus inicios se ha debido en gran medida a las investigaciones que se dieron en torno a los estudios de los genes y sus productos, la elucidación de la estructura del ADN, el desciframiento del código genético o los mecanismos de regulación genética, entre otros. Así pues, la primacía del ámbito genético, cuyo origen se puede ubicar en la consolidación de la denominada Síntesis Moderna, adquiere características novedosas con el desarrollo de la Biología molecular (Keller 2000; Falk 2009).

Desde luego, qué es una reducción y cuáles son sus implicancias ha sido objeto de profundo debate en la filosofía de la Biología. Para abordar el asunto, como punto de referencia se suele tomar la propuesta de Ernst Nagel (1961) dada en el marco de la filosofía de la ciencia, la cual tuvo especial notoriedad en dicho campo. A grandes rasgos, la versión nageliana plantea que la reducción es un tipo de explicación que sucede entre dos teorías para el caso en que una teoría pueda ser deducida de la otra a través de determinadas "leyes puente". En otras palabras, reducir es deducir desde las leyes de una teoría $(T)$ reductora, las leyes de una teoría $\left(T^{\prime}\right)$ reducida. Sin embargo, en su aplicación al ámbito biológico, el planteo ha presentado algunos inconvenientes. Algunas críticas realizadas apuntan a que los elementos teóricos involucrados en la relación de reducción en biología no son teorías ni leyes a la manera que las entiende Nagel, ni mucho menos parece mediar entre ellos una explicación "nomológico-deductiva" (ver Kaiser 2012; Van Riel y Van Gulick 2018). Así pues, alejándose de tal postura, se han propuesto otros sentidos de la noción de reducción, aunque en ningún caso se haya consolidado una versión alternativa con el mismo grado de aceptación por parte de la comunidad filosófica (Wimsatt y Sarkar 2006). No obstante, los debates han dilucidado diferentes tipos de reducciones. Así, entre las visiones que consideran que el ámbito reducido es explicado por otro dominio de la ciencia - es decir, que piensan a la reducción como un tipo de explicación - se distinguen aquellas aún asociadas al modelo de Nagel y aquellas que se distancian de dicho modelo. Las primeras son denominadas como propias del "reduccionismo teórico", mientras que las segundas están englobadas bajo la categoría de "reduccionismo explicativo". A su vez, las visiones que consideran que el vínculo reductivo ocurre en los procedimientos de las investigaciones discuten elementos del considerado "reduccionismo metodológico". Asimismo, los puntos de vista que reflexionan sobre la reducción como vínculo entre entidades materiales refieren al llamado "re- 
duccionismo ontológico" o "constitutivo" (Mayr 1988; Sarkar 1992; Callebaut 1995, para otras clasificaciones también Caponi 2004). Sin dudas, aunque se puede analíticamente distinguir cada uno de ellos, los distintos tipos de reducciones tienen puntos en contacto y en las investigaciones suelen presentarse de manera conjunta.

Desde luego, tanto la genética como la Biología molecular han tenido un lugar en debates de los distintos reduccionismos mencionados. En el caso de la pregunta sobre las relaciones entre la Biología y la Física, se ha llegado a cierto consenso, fortalecido a partir del desarrollo de la Biología molecular, en considerar que todas las entidades biológicas están constituidas por elementos físicos. Tal postura fisicalista (y por ende anti-vitalista) no agota, sin embargo, las preguntas ontológicas sobre las relaciones entre Biología y las disciplinas de los niveles inferiores de organización. En efecto, las perspectivas que se ocupan en indagar sobre las reducciones explicativas incorporan la idea - ausente en las versiones nagelianas - de que las explicaciones reductivas en Biología implican el vínculo entre el todo y sus partes constituyentes (Sarkar 1992; Kaiser 2015; Bringandt y Love 2017). Aun así, las características de dicho vínculo es motivo de debate permanente. Por su parte, la genética ha sido protagonista de discusiones propias del reduccionismo teórico, principalmente a partir de la pregunta por la posibilidad de reducción de la genética clásica en la genética molecular (por ejemplo, Hull 1972). Sin embargo, su rol hegemónico hacia el seno de la Biología, señalado por diversos autores en el campo de Filosofía de la Biología (ver Rose et al. 1984; Keller 2000; Noble 2006; Jablonka, Lamb y Zeligowski 2013; entre otros) no ha sido ampliamente abordado por los debates sobre reduccionismo en Filosofía de la Biología (algunos ejemplos pueden ser Carrier y Finzer 2006; Rosenberg 2006). Algunos de los aportes más interesantes que se han dado al respecto provienen de las discusiones sobre reduccionismo explicativo, de mayor interés para la comunidad filosófica actualmente.

Uno de los aportes más claros que se han realizado en las últimas décadas respecto a la problemática del reduccionismo, y que a su vez aborda la situación de la genética y de la Biología molecular, ha sido dada por el filósofo Sahotra Sarkar (Sarkar 1998, 2005; Tauber y Sarkar 1992; Wimsatt y Sarkar 2006). Entre sus principales contribuciones se encuentra su énfasis en los que él denomina como "asuntos sustantivos" de una reducción explicativa, aquellos aspectos de la reducción que consideran la interpretación de los argumentos científicos en referencia a qué asumen acerca del mundo y cómo representan los sistemas bajo estudio. En su libro Genetics and reductionism (1998) el autor apunta a clarificar dos tipos de relaciones: por un lado, aquella entre el campo disciplinar de la Biología en su conjunto con respecto a la Física y la Química; por otro, el vínculo entre la genética y el resto de los campos de conocimiento de la Biología. Ambos tipos de relaciones, a las que denomina propias del reduccionismo físico y reduccionismo genético respectivamente, son detalladas observando en cada caso en qué sentido se podrían considerar propiamente como 
reducciones y cuáles serían las ventajas y desventajas de que así sean.

De tal manera, nos interesa discutir aquí el riguroso e influyente análisis de Sarkar, su modelo de reducción y sus planteos en torno a la genética y a la Biología molecular. En términos generales su perspectiva exhibe numerosas ventajas heurísticas, aunque presenta algunas dificultades al intentar utilizarla para caracterizar el estado de situación de gran parte de la genética contemporánea. Entre sus principales problemas encontramos que la construcción separada de los reduccionismos genético y físico desestima profundas interconexiones que entre ambas perspectivas existen desde mitad del siglo $\mathrm{XX}$, momento en el cual la genética mayormente ha devenido molecular. Como veremos, Sarkar se expresa en contra de la mezcla de ambos reduccionismos, argumentando que en tales casos han surgido programas de investigación de "dudosa base científica" como el proyecto genoma humano (Gilbert y Sarkar 2000; Sarkar 1998; Sarkar y Tauber 1993; Tauber y Sarkar 1992). A nuestro modo de ver, sin embargo, los programas que mezclan ambas perspectivas no son una anomalía - el propio proyecto genoma humano no lo era - , sino que constituyen una importante perspectiva en el quehacer biológico.

Así pues, en el presente trabajo intentaremos dar una caracterización de las posiciones que enfatizan el rol de los genes en el estudio de los seres vivos desde discusiones propias del reduccionismo. Particularmente, nos proponemos analizar y debatir las principales características de la visión sarkariana y, empleando su perspectiva, buscar proponer una alternativa que describa mejor el reduccionismo genético contemporáneo. Con tal objetivo, en la próxima sección reseñaremos y debatiremos la posición de Sarkar en relación con aspectos epistemológicos, metodológicos y ontológicos de la reducción. Estos elementos son parte de la base de su modelo el cual será considerado en una tercera etapa, donde también profundizaremos la visión del autor en torno al reduccionismo genético y el molecular, y en donde plantearemos algunas diferencias con su perspectiva. En base a lo expuesto, en un cuarto momento, formularemos nuestra propuesta de modelo de reduccionismo. Por último, se concluirá con algunos comentarios sobre el recorrido del trabajo.

\section{Reducciones, reduccionismos y Sarkar}

Los diversos ataques o defensas de las posiciones reduccionistas presentan como punto problemático el no poseer un lenguaje común sobre a qué llaman "reducción". Para resolver este problema diversos autores (Sarkar entre ellos) ofrecen sus propias caracterizaciones y modelos, pero aun así es preciso señalar que cada propuesta es construida según determinados propósitos. En este sentido, Sarkar señala:

Las preguntas sobre si un modelo de reducción se supone que captura la estrategia de investigación que se estaba o está llevándose a cabo, o si pre- 
tende capturar la estructura de las explicaciones que podrían resultar, deben mantenerse separadas. (Sarkar 1992, p. 182)

En el primer caso, advierte el autor, calificar a una visión de reduccionista significaría indicar que persigue que sus investigaciones sean reducciones, lo cual presenta una dimensión empírica en tanto puede fallar ${ }^{1}$. En el segundo, decir que una disciplina o área de conocimiento es reduccionista implicaría afirmar que en su proceder obtiene reducciones como resultado. Esta última perspectiva es aquella que le interesa a Sarkar, en tanto afirma "que al menos la estructura de explicaciones en biología molecular es reduccionista y él [Sarkar] proporciona el modelo [...] con el fin de capturar el sentido en el que lo es" (Sarkar 1992, p. 185).

Sin dudas, la apreciación de Sarkar pone en debate la relación existente entre aspectos epistemológicos y metodológicos de la reducción. Al respecto, se ha señalado que las explicaciones obtenidas se encuentran profundamente ligadas con las metodologías empleadas (Wimsatt 2006), aunque algunos autores consideran que no necesariamente una metodología reduccionista implica una explicación reduccionista (Sarkar 1992; Kaiser 2015). Esta última perspectiva elige remarcar Sarkar y por ello opta por intentar dar cuenta de la estructura de la explicación reduccionista independientemente de aspectos metodológicos. Por nuestra parte, más allá de ciertos desacoples que puede haber entre metodología y explicación reduccionista, preferimos no dejar del todo de lado la conexión entre ambos aspectos. Uno de nuestros puntos de partida es que efectivamente se persigue de manera más o menos manifiesta que existan explicaciones reduccionistas centradas en los genes. Tales explicaciones pueden ser fallidas, espurias o de dudosa base científica (en términos de Sarkar 1998) o "inadecuadas" (en palabras de Kaiser 2015) en algunos sentidos, pero aun así persisten como legítimas dentro de la comunidad biológica (ver Krimsky y Gruber 2013). Intentaremos a partir del modelo de Sarkar poder dar cuenta de la estructura de dichas explicaciones.

Uno de los elementos que nos permite pensar el vínculo entre cómo se persiguen reducciones y las reducciones propiamente dichas es la novedosa idea que trae Sarkar acerca de la importancia de las representaciones en ciencias. Esta propuesta proviene de lo que para el autor constituye la naturaleza de una explicación:

Se asumirá que una explicación comienza con una representación del sistema. La distinción entre un sistema y una representación es importante. Lo que en el lenguaje cotidiano se llamaría el "mismo sistema" puede tener más de una representación, dependiendo del contexto de investigación [...] la elección de una representación no es trivial; una explicación puede fallar debido a una mala elección de la representación. Las representaciones a menudo se indican en forma de diagrama. (Sarkar 1998, p. 41-42. Las cursivas son del autor.) 
En pocas palabras, la propuesta es que los fenómenos naturales son diagramados, conceptualizados gráficamente o simbolizados estableciendo representaciones de aquello que se estudia o pretende estudiar, y que son dichas representaciones las que hay que considerar al momento de reflexionar sobre la reducción (Sarkar 1998; Bringandt y Love 2017). Desde luego, al hacer énfasis en las representaciones, Sarkar se aleja en gran medida de las posiciones tradicionales (propias del reduccionismo teórico) en su concepción sobre las explicaciones. Desde nuestro punto de vista, las representaciones no sólo se dan antes de iniciar una explicación, sino que son particularmente buscadas. Es decir, se persigue que las explicaciones asuman determinado tipo de representaciones. Este aspecto no queda claro en Sarkar o quizás no es de su interés dado que prefiere distanciarse de aspectos metodológicos. Sin embargo, para nosotros es preciso resaltarlo en la medida que de otra manera no parece entenderse la permanencia de posiciones gen-centristas habiendo tantas críticas a tales visiones.

Otra de las cuestiones que ha estado en debate sobre la definición de reducción ha sido el vínculo entre asuntos epistemológicos y ontológicos. Al respecto, Sarkar intenta enfáticamente separar ambos aspectos, pero aun así debe reconocer los fuertes vínculos que presentan al analizar el reduccionismo en Biología. En este sentido, el autor señala que incluso las posiciones más débiles del fisicalismo conllevan en algún grado hacia posiciones propias del reduccionismo explicativo: "Cualquier suposición de reduccionismo constitutivo genera inmediatamente un programa de investigación, a saber, el de intentar explicar las propiedades de las entidades de nivel superior en términos de las propiedades de las entidades de nivel inferior que los constituyen" (Sarkar 1992, p. 182). En efecto, al plantear su modelo (1998) necesita tomar posición sobre dos de los fisicalismos más reconocidos, el denominado token physicalism y aquel conocido como "sobreveniencia" (supervenience). La primera perspectiva no presenta ninguna controversia biológica ni filosófica. En términos de quien acuñó el término: "Token physicalism es simplemente la afirmación de que todos los eventos de los que hablan las ciencias son eventos físicos" (Fodor 1974, p.100). La segunda propuesta, ontológicamente más fuerte, podría resumirse en el eslogan "No puede haber una diferencia en A sin una diferencia en B" (McLaughlin y Bennett 2018) donde, en el contexto biológico, A es un fenómeno o estado o propiedad biológica y $\mathrm{B}$ un fenómeno o estado o una propiedad física subyacente. Este último argumento ha sido empleado por posiciones anti-reduccionistas en tanto es consistente con la idea de que un estado en un nivel superior se corresponda con varios (o infinitos) estados de los niveles inferiores, haciendo imposible la explicación desde los niveles inferiores a los superiores (postura conocida como de realizabilidad múltiple; ver Rosenberg 1985). Pese a ello, Sarkar desestima que tales posiciones aporten a la reflexión sobre el reduccionismo explicativo, tales suposiciones ontológicas serían una base evidente de discusión: "Obviamente, todos los modelos de reducción explicativa y teórica que hacen afirmaciones ontológicas generalmente satisfacen los requisitos 
de ambos modelos" (Sarkar 1992, p. 181).

De tal forma, de la visión de Sarkar se desprende que pareciera haber cierto acuerdo en considerar que existe algún estado de los niveles inferiores asociado con algún estado de los niveles superiores, y que en todo caso son las características de dicho vínculo el objeto del debate. Sin embargo, resulta preciso aclarar si tales estados son situaciones biológicas particulares (tokens) o si son clases de estados (types). Llamativamente, Sarkar no aborda este debate olvidando la posición fisicalista conocida como type physicalism (Fodor 1974), la cual resulta relevante considerando que las explicaciones biológicas generalmente buscan cubrir clases de fenómenos y no situaciones puntuales. Aunque sería injusto decir que Sarkar desconoce tal situación, sí es preciso señalar que una de las formas más extendidas de hacer referencia a clases de estados o fenómenos es a través de modelos biológicos, los cuales no son tenidos en cuenta por el autor en su exposición. Desde luego, la discusión en torno al rol de los modelos biológicos nos retrotrae en alguna medida a cuestiones metodológicas, pero no hay que perder de vista que en la selección de modelos también se adopta un sistema por sus propias características ontológicas (más simple, por ejemplo) y a partir del cual se pretende extrapolar o establecer generalizaciones.

Los fisicalismos referidos, en tanto aceptan que las entidades biológicas están constituidas por entidades materiales, suponen cierta separación en niveles de organización. Para Sarkar (1998) dichos niveles constituyen un elemento clave en las explicaciones biológicas, lo cual ha sido motivo de discrepancia con la tradición nageliana centrada en el vínculo entre teorías. La distancia con tal perspectiva puede ser debida a las diferencias en el tipo de reducción considerada. En efecto, a Sarkar (y a nosotros) nos interesa aquellas denominadas como "reducciones internivel" y no las "reducciones sucesionales", que refieren a la pregunta de si un campo ulterior reduce a otro anterior temporalmente, como puede ser la cuestión de si la genética molecular reduce a la genética clásica. Al respecto Sarkar señala: "Los modelos de Nagel y Schaffner, aplicados a las reducciones y explicaciones entre niveles, explícitamente no incorporan la idea básica de que una explicación reductiva es la explicación de un todo en términos de sus partes" (Sarkar 1992, p. 176). De esta manera, al otorgar importancia a la relación parte-todo, el autor introduce aspectos ontológicos en su modelo de reducción explicativa.

Otra de las formas del autor de incluir el rol de las entidades - y a su vez, otro de los puntos que lo alejan de las versiones nagelianas - es el reconocimiento de que en Biología las entidades pueden definirse de manera distinta según los contextos explicativos. Sarkar destaca pues, que hay un uso sistemático de aproximaciones. Por ejemplo, en las explicaciones propias de la Biología molecular, muchas veces los átomos son considerados esferas rígidas, lo cual ciertamente es una aproximación problemática — dado que la Química y la Física rechazarían tal propuesta - , pero fructífera, en la medida que posibilitan incluso predicciones acertadas (Sarkar 1998). 
El autor sistematiza el uso de aproximaciones aclarando así que pueden ser implícitas o explícitas; corregibles, incorregibles en la práctica o incorregibles en principio; sus efectos estimables o no estimables en la práctica o en principio; justificables matemáticamente o por otros procedimientos, o no; pueden ser contexto dependientes o independientes; pueden involucrar suposiciones contrafácticas o no. Tal caracterización permite observar que ciertas aproximaciones pueden no ser filosóficamente cuestionables (si, por ejemplo, son explícitas, corregibles, estimables, justificadas, contexto independientes y sin suposiciones contrafácticas), mientras que otras sí lo pueden ser en contextos de reducción.

En resumidas cuentas, los cruces entre aspectos epistemológicos, metodológicos y ontológicos son múltiples y los límites entre ellos muchas veces se plantean de acuerdo con los intereses e intenciones que cada autor pretende dar cuenta. Por nuestra parte, intentaremos seguir a Sarkar en intentar capturar la estructura de las explicaciones reduccionistas a partir de cómo éstas son representadas, pero en lugar de buscar presentar un modelo general de reducción, nuestro interés se encuentra en aquellas explicaciones centradas en los genes.

\subsection{El modelo sarkariano}

Teniendo en cuenta los aspectos presentados, el autor desarrolla dos "intuiciones" que estima se encuentran en toda reducción explicativa: la existencia de dos dominios en los cuales uno da cuenta del otro, y que existe una representación jerárquica en el que las explicaciones van desde la base hacia la cima. Tales intuiciones llevan a Sarkar a plantear una serie de criterios para evaluar si una determinada explicación consiste en una reducción. Los tres criterios para analizar una reducción sustantiva son los siguientes: fundamentalismo, jerarquía abstracta y jerarquía física (Sarkar 1992, 1998) (Figura 1). En el caso de cumplir sólo el primer criterio, la reducción es considerada débil. Si cumple los primeros dos, se la denomina reducción de la jerarquía abstracta. Si cumple los tres criterios, se tratará entonces de una reducción fuerte.

El primer criterio se sustenta en la intuición de que toda reducción se basa en que existe otro dominio, otro campo explorado por otra tradición de investigación que puede proveer un entendimiento más profundo que el que se está estudiando. Tal otro campo es, entonces, considerado más "fundamental" (Dominio-F en adelante, como lo denomina Sarkar). A su vez, desde el campo más fundamental se tienen que reconocer factores y reglas que se utilizan para dar cuenta de elementos del otro dominio (reglas-F) y donde lo explicado puede derivarse de estos factores y reglas utilizando alguna justificación lógica, matemática, computacional o a partir de diversos tipos de aproximaciones, tal como veíamos en la sección anterior.

Los criterios enfatizan que en las explicaciones reductivas la forma de representar 
el sistema tiene un orden jerárquico, es decir, que se reconocen diferentes niveles. Los factores explicativos, aquellos considerados más relevantes, se encuentran en los niveles inferiores, y las explicaciones van desde el nivel inferior hacia el superior. En el criterio de la jerarquía abstracta, los niveles son abstractos, sin correlato físico. Aquel de la jerarquía Física involucra entidades en el espacio físico, es decir, se cumple cuando en la jerarquía abstracta hay coincidencia con los niveles de organización de la materia. Este último criterio responde a la necesidad de incluir las relaciones parte-todo en las explicaciones reductivas.
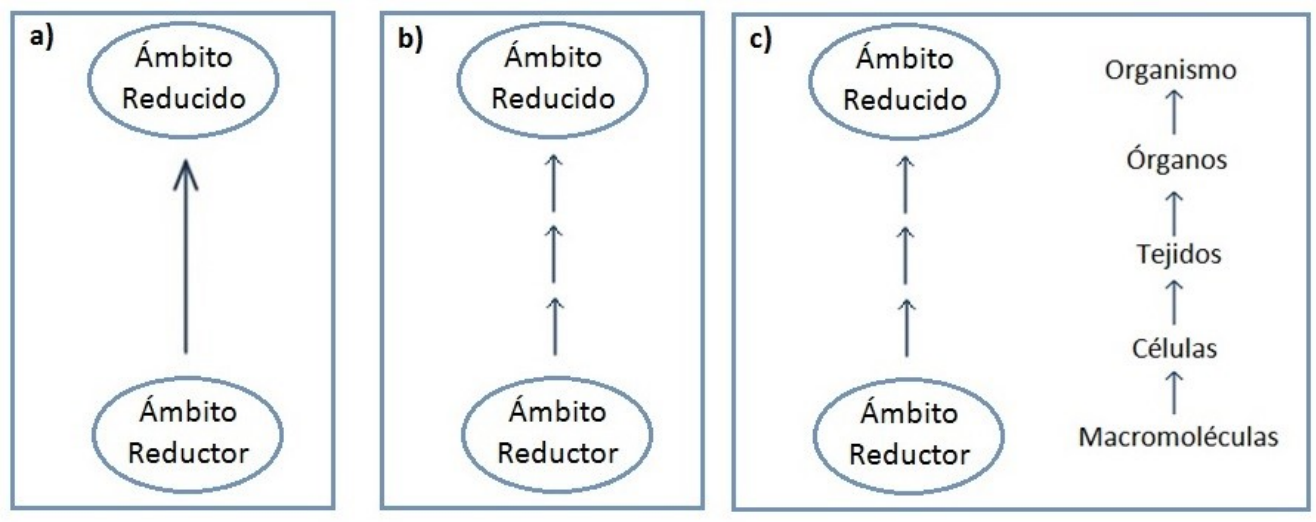

Figura 1: Criterios sustantivos de Sarkar. Los dominios se encuentran señalados como "ámbito reducido" y "ámbito reductor", siendo éste último el dominio-F. Las flechas indican el sentido de la explicación. a) Fundamentalismo, b) Jerarquía abstracta, c) Jerarquía física.

\section{Reduccionismo genético y reduccionismo físico}

El modelo expuesto es empleado por Sarkar para analizar lo que él considera dos tipos de reduccionismos presentes en la disciplina biológica a los cuales denomina "reduccionismo genético" y "reduccionismo físico". El primero alude al punto de vista que otorga primacía al ámbito genético al momento de realizar explicaciones de los fenómenos biológicos. El segundo es aquel que refiere al vínculo entre Biología, Física y Química, y que propone que las explicaciones en Biología deben partir del nivel molecular.

La caracterización de Sarkar del reduccionismo genético se basa en estudios realizados por la genética clásica (Sarkar 1998). En tal reduccionismo, el campo fenotípico es reducido al genotipo (Dominio-F), y éste provee las reglas-F básicas a partir de los análisis de ligamiento y de segregación. El criterio fundamentalista se cumple, 
según el autor, a través de una serie de aproximaciones que se realizan en los análisis mencionados, por ejemplo, la suposición de que la penetrancia de un alelo es igual a uno en los análisis de ligamiento. El segundo criterio, el correspondiente a la jerarquía abstracta, es construido como "jerarquía genética". En la base de tal jerarquía se encontrarían los alelos, luego los loci; y subiendo en los niveles, los fenotipos de los organismos. Lógicamente, las explicaciones desde el punto de vista reduccionista irían desde los alelos hacia los fenotipos. Sarkar destaca que la jerarquía genética por él construida no presenta un correlato espacial, lo cual es razonable en tanto la genética clásica prescinde de la naturaleza fisicoquímica de los genes. El reduccionismo genético es, entonces, un reduccionismo abstracto (Sarkar 1992, 1998).

Una vez descripta la estructura de la explicación reduccionista genética, Sarkar se posiciona al respecto. Así pues, sostiene que los análisis de ligamiento y de segregación son muy útiles pero que pueden dar lugar a explicaciones espurias a partir de conceptos como expresividad variable o penetrancia incompleta. Sin dudas, como Sarkar mismo señala, tales estrategias resultan polémicas cuando se trata de rasgos complejos en seres humanos incluyendo enfermedades mentales como la esquizofrenia o la depresión. Es menester indicar para nuestros objetivos que tales explicaciones espurias presentan actualmente una base molecular que Sarkar no toma en cuenta bajo su caracterización de reduccionismo genético.

Por su parte, en el reduccionismo físico los campos involucrados serían la Biología, por un lado, y como dominio-F, la Física y/o la Química - Sarkar dice, la Física de las macromoléculas. El criterio fundamentalista es cumplido a través de diversas aproximaciones realizadas por la Biología molecular. Entre las más comunes se encuentran aquellas realizadas en relación con los modelos atómicos, considerando átomos esféricos y con superficies definidas. El criterio de la jerarquía abstracta es analizado a través de cómo se representan ciertos mecanismos moleculares. Su estrategia consiste en elaborar una figura en la cual esquematiza mecanismos moleculares, tomando como ejemplo al modelo de operón lac, y en tal gráfico reconoce una representación jerárquica. Por último, Sarkar observa que la representación gráfica presenta correlato espacial en tanto las moléculas (ADN, proteínas) pertenecen a un nivel de organización menor que el explicado (nivel celular). De tal forma, el reduccionismo físico es, para Sarkar, un reduccionismo de tipo fuerte.

Nuevamente, el autor se posiciona en relación a las explicaciones reduccionistas, en este caso físicas, las cuales parecen ser estimadas de manera positiva. Propone así, con ciertos recaudos, al reduccionismo físico como un programa de investigación apropiado en el cual se pueden reconocer sus éxitos en la Biología molecular (Sarkar 1998). Sin embargo, Sarkar intenta ser precavido y exhorta a no mezclar los reduccionismos genético y físico. En este sentido, el autor remarca que el reduccionismo físico no requiere ninguna suposición acerca de la primacía del ADN o de los genes en las explicaciones de los comportamientos biológicos: "El reduccionismo físico es 
una tesis sobre la relación de la biología con la física; es neutral acerca del estado de la genética dentro de la biología" (Sarkar 1998, p. 174).

Nuestro interés, sin embargo, aparece precisamente en aquella mezcla que Sarkar llama a evitar; esto es, aquel reduccionismo que se da en el marco de la genética molecular. La intención pues, es intentar capturar la estructura de las explicaciones "gen-centristas" que se dan a partir del advenimiento de técnicas moleculares a mediados del siglo XX. En tales explicaciones el ADN ocupa un lugar central, inexistente en la genética clásica que carece de referencias a entidades físicas. En esta dirección, otros autores también se distancian de Sarkar. Marie Kaiser, por ejemplo, analizando la obra del autor que hemos elegido resalta: "[... ] Sarkar se centra en las explicaciones genéticas como se pueden encontrar en la genética clásica [...]. Las explicaciones genéticas que me interesan aquí son diferentes. Se basan en la noción de un gen molecular, no en el concepto de un gen mendeliano [... ]" (Kaiser 2015, p. 206). A su vez, otra de las características distintivas de dichas explicaciones es la alusión a la noción de "información genética", que ubica al ADN como único depositario de información biológica (Keller 2000; Jablonka, Lamb y Zeligowski 2013).

Desde luego, Sarkar no desconoce la realidad material de la genética contemporánea ni la importancia de la noción de información genética, asuntos que aborda ampliamente en el Capítulo 6 de su libro Genetics and Reductionism (1998). Allí, dedica esfuerzos para mostrar que el reduccionismo de la genética molecular es un caso más de reduccionismo físico. Con tal argumentación, cualquier asunto propio de un reduccionismo genético molecular o exhibe las mismas características del reduccionismo físico - donde lo propiamente genético se diluye - o ya se encuentra presente en la genética clásica - y allí hay que aplicar los criterios propios del reduccionismo genético. La posición del autor se fundamenta en motivos históricos en tanto interpreta que la genética molecular proviene principalmente de la aplicación de aquellas investigaciones que considera que dieron origen a la Biología molecular en su conjunto, los "estudios estructurales" - aquellos que derivan de los trabajos de Pauling y colaboradores. Sin embargo, otra perspectiva histórica posible es que la genética ha ocupado un rol central en la construcción de la biología molecular (Keller 1990), siendo un ejemplo de ello que uno de los elementos teóricos más relevantes de la historia de la genética - el dogma central - sea denominado por Francis Crick como "dogma central de la Biología Molecular". Sin embargo, para él los caminos hacia la biología molecular desde la genética o desde los programas de investigación que resaltan la noción de información son "otras rutas hacia la Biología Molecular" (1998, p. 139). En esta elección soslaya los importantes aportes de las investigaciones provenientes de la genética en la construcción no sólo del reduccionismo contemporáneo, sino también de la propia Biología molecular.

Pero más allá de la discusión histórica, ciertas explicaciones reduccionistas de la genética molecular no parecen ajustarse correctamente a la separación entre reduc- 
cionismo genético y reduccionismo físico. En el caso del proyecto genoma humano (PGH) Sarkar ensaya tal argumento:

Los defensores del PGH han prometido muchos avances en biología y medicina. Han confiado en gran medida en el éxito de la biología molecular, el poder de la explicación molecular, para justificar su fe y convencer a las agencias políticas responsables del desembolso de fondos públicos. Sin embargo [...] estos éxitos son principalmente éxitos del reduccionismo físico. No obstante, en un ejemplo bastante notable de combinación conceptual, los defensores del PGH han utilizado estos éxitos para justificar una tesis general del reduccionismo genético. Es poco probable que el PGH cumpla con casi cualquiera de sus promesas, científicas o médicas, pero los problemas no son del reduccionismo físico. Más bien, son problemas que han plagado el reduccionismo genético desde la década de 1920 [... ]. (Sarkar 1998, p. 174)

Como se observa, el autor intenta separar tajantemente ambos reduccionismos y atribuye los aspectos criticables del PGH al reduccionismo genético propio de la genética clásica. A nuestro parecer esta perspectiva no resulta convincente y olvida principalmente el rol que la noción de "información genética" tiene en la conformación de proyectos biotecnológicos como el PGH. A su vez, la cantidad de fondos y el lugar de las agencias científicas y políticas involucradas en el PGH llaman a pensar que no representan en absoluto una perspectiva aislada en el quehacer científico. Precisamente tal punto de vista es el que queremos entender y caracterizar.

\section{El reduccionismo genético molecular}

La propuesta sarkariana nos permite exponer lo que para nosotros es la estructura de las explicaciones propias de un reduccionismo genético molecular. Para acotar el análisis, empleamos principalmente conceptos y elementos teóricos de uno de los períodos más significativos en la constitución de la genética molecular, las décadas del '50 y '60, rescatando principalmente aquellas "otras vías hacia la Biología molecular" que Sarkar deja de lado. No obstante, consideramos que más allá de las importantes transformaciones teóricas y metodológicas, las conceptualizaciones originadas en aquellos años continúan en gran medida vigentes en la Biología contemporánea. A continuación, caracterizamos entonces a dicho reduccionismo en sus tres criterios, siendo el fenotipo el ámbito reducido y el genotipo, el reductor. Proponemos reglas-F y una jerarquía abstracta acordes a una intersección entre genética y biología molecular, observando a su vez, su vínculo con los niveles de organización de la materia. 


\subsection{Fundamentalismo}

Según Sarkar, la noción de fundamentalismo proviene de la idea de que las explicaciones reductivas se basan en que un determinado dominio de investigaciones otorga un mejor entendimiento que otro, siendo el primero entonces más fundamental que el segundo. En nuestra caracterización, el dominio-F es el campo genotípico y el reducido, el fenotípico. Proponemos que una de las reglas-F que otorgan primacía epistémica al dominio genotípico sobre el fenotípico es la siguiente aproximación: el gen "clásico" es considerado la misma entidad que el gen "molecular". A su vez, esta aproximación también satisface la intuición de que el fundamento es uno solo y no muchos (Kaiser 2015).

Aquí es preciso mencionar que, más allá de las dificultades de cualquier definición, en el área de filosofía de la biología se distinguen diferentes nociones de gen, principalmente aquella asociada a la genética clásica y la propia vinculada al ámbito molecular. La primera entendería al gen de manera relacional con el fenotipo, por ejemplo, "gen de los ojos azules" (aún con sus matices, ver nociones de "gen como generador de diferencias" en Keller 2000; "gen-P" en Moss 2003 y "el concepto clásico del gen" en Waters 1994). En contraste, la segunda no asumiría al gen en su vínculo con el fenotipo, sino como secuencia de nucleótidos cuya función se encontraría asociada a otros tipos de moléculas, tales como el ARN o las proteínas (ver "el concepto molecular del gen" en Waters 1994 y "gen-D" en Moss 2003). Históricamente, la conceptualización del gen molecular deriva de la "molecularización" del gen tal como era entendido en la genética clásica (Waters 1994). Así pues, resulta lógico que en un momento histórico ambas nociones no sean distinguibles y se atribuyan cambios fenotípicos a cambios en el ADN. Sarkar mismo señala tal situación:

No debería sorprender que, una vez que el gen se caracterizó físicamente, el "gen molecular" ha sido cotidianamente confundido con el "gen clásico". Para el biólogo molecular, "gen" generalmente se refiere a fragmentos de ADN sin importar si el contexto es clásico o molecular. [... ] Quizás la confusión conceptual más significativa que ha resultado de esta combinación es que el gen, cuando se concibe como un fragmento de ADN, necesita notarse incluso como algo que haga alguna diferencia fenotípica a nivel organísmico. (Sarkar 2002, p. 192-193)

Como se observa, para Sarkar existe una confusión entre ambas nociones de gen en tanto ello sirve hacia sus objetivos de presentar el reduccionismo físico y el genético por separado. Sin embargo, desde nuestro punto de vista, la "confusión" señalada resulta habitual en la visión de numerosos científicos en programas de investigación contemporáneos (como muestran Stotz y Griffiths 2004). Así pues, para nosotros no resulta meramente un equívoco, sino una manera de concebir la naturaleza de los genes. Por ello, consideramos que en tales casos hay una aproximación que tiende a 
unificar ambas nociones, de manera que el gen es definido vinculado al fenotipo y como secuencia de nucleótidos.

La propuesta de aproximación apunta a mostrar que las dos nociones, que operan en contextos explicativos distintos, en ciertas situaciones se presentan de manera asociada. En ocasiones, las explicaciones de orden molecular buscan relacionar secuencias de nucleótidos con determinados fenotipos; en otras, explicaciones que se centran en los fenotipos asumen o aspiran a que una secuencia de ADN en particular dé cuenta de ellos. Ciertamente, en qué medida es o no adecuada la relación entre una secuencia de $\mathrm{ADN}$ y un determinado fenotipo en una explicación depende del caso y de ciertos límites contextuales. Para la anemia falciforme -donde una mutación puntual permite dar cuenta del fenotipo anémico- no parece ser problemática la relación entre el gen y el fenotipo planteado, mientras que en otros contextos sí puede serlo, con relaciones genotipo-fenotipo más complejas, por ejemplo, para padecimientos mentales como la depresión ${ }^{2}$. De tal manera, de acuerdo con Sarkar, es preciso observar si la aproximación entre gen clásico y molecular es explícita o implícita, sus efectos estimables o no, si es corregible o no, si se encuentra justificada por ciertos procedimientos o matemáticamente o no, si involucra suposiciones contrafácticas o no. En los ejemplos (anemia y depresión), las aproximaciones presentan implicancias distintas pero en ambos casos cumplirían el criterio fundamentalista si asocian secuencias de ADN con fenotipos.

\subsection{Jerarquía abstracta}

El criterio de la jerarquía abstracta en un reduccionismo genético molecular puede ser analizado a partir del flujo de información entre el genotipo y el fenotipo, el cual consideramos que ordena la forma de representación de dicha relación. Nuevamente aquí se nos presenta el problema de la definición ya que, como varios autores han expuesto, el concepto de información genética presenta cierto grado de polisemia (Griffiths 2001; Sarkar 2005; Godfrey Smith, Sterenly 2016). A los fines de nuestro trabajo, nos parece destacar principalmente el concepto de información vinculado a la noción de "código genético" elaborada por Francis Crick en su postulado del dogma central (Sarkar 1996; Exteberria Agiriano y García Azkonobieta 2004). En efecto, desde el dogma central, el vínculo entre el genotipo y el fenotipo se modifica: pasa de ser una relación simple a una de naturaleza compuesta: entre el genotipo y las proteínas, y entre las proteínas al fenotipo (Morange 2000; Godfrey-Smith 2004). La jerarquía entonces comprende estos dos intervalos de flujo de información.

La noción de información ligada al "código genético" es aquella célebre explicitada por Francis Crick (1958): "Información significa aquí la determinación precisa de la secuencia, o bien de las bases en el ácido nucleico o de residuos de aminoácidos en la proteína" (p. 153). Esta definición se restringe al primer intervalo de la jerar- 
quía - entre el genotipo y las proteínas - y es sin dudas, el ámbito cuyo estudio ha dado mayor éxito y prestigio tanto a la genética como a la Biología molecular, principalmente a mediados del siglo pasado. En efecto, queda en estos años establecido y caracterizado el flujo de información en el primer intervalo de la jerarquía a partir de los procesos de transcripción (de ADN a ARN) y traducción (de ARN a proteínas) todavía en gran medida vigentes.

Pero a su vez, es preciso destacar que en Biología se suele decir que existen genes que "codifican para" un determinado fenotipo, lo cual extiende el sentido de la noción de información más allá de las proteínas. Sin embargo, no existe una definición clara o bien un mecanismo único que dé cuenta del segundo tramo de la jerarquía (circunstancia que ha dado cierto debate filosófico, por ejemplo en Sarkar 2004). Una de las respuestas a tal falta de definición es la consideración de que el intervalo proteínas-fenotipo ya se encuentra en alguna medida definido por el primer intervalo. En esta dirección, Crick (1958), en el mismo escrito en el que formula el dogma central plantea: "Se puede argumentar que estas secuencias [de aminoácidos] son la más delicada expresión posible del fenotipo de un organismo y que grandes cantidades de información evolutiva pueden estar escondidas dentro de ellas" (p.142). Así pues, la información necesaria para explicar las funciones, comportamientos y morfologías observables a nivel organismo ya se encontraría contenida en la secuencia de aminoácidos, que a su vez se encuentra establecida en la secuencia de ADN. De tal forma, se asume que sólo el conjunto de proteínas y sus funciones establecen de alguna manera las características observables de los organismos.

La misma situación podemos encontrar en el empleo de otro concepto de información, aquel del "programa genético" surgido a partir de los estudios que plantearon el conocido modelo de regulación genética operon lac (Jacob y Monod 1961). La propuesta de François Jacob y Jacques Monod es que tal modelo permite dar cuenta de cómo se produce la ontogenia de los organismos. De esta manera, por "información" se entendería el conjunto de instrucciones que se deben realizar para que un organismo se desarrolle, hallándose éstas in toto en el ADN del cigoto. Así lo expresa el mismo Monod: "La información estaba presente, pero sin expresar, en los constituyentes. La construcción epigenética de una estructura no es una creación sino un reveleación" (1970, p. 102; las cursivas son originales). Como se advierte, a pesar de que el operon lac especifica las características de la regulación de la expresión genética (es decir, a la coordinación de la producción de proteínas), la noción de información asociada al programa genético se extiende más allá del primer intervalo de la jerarquía abstracta, sin definir claramente cómo una vez producidas las proteínas se llega a adquirir un determinado fenotipo.

De tal modo, observamos que tanto la noción de código genético como la referida al programa genético conciernen al ámbito del primer tramo de la jerarquía abstracta, pero que se emplean para dar cuenta de los fenotipos de los organismos. Así, el 
segundo intervalo de la jerarquía -el pasaje de información desde las proteínas a los fenotipos- no es tenido en cuenta en ambas concepciones ya que aparece incluido como mero resultado de la función de las proteínas.

\subsection{Jerarquía Física}

Una de las características que buscamos enfatizar con nuestra propuesta es que el reduccionismo genético de la Biología contemporánea emplea entidades postuladas por las teorías físicas y químicas. Observamos en este sentido que se cumple la relación parte-todo tal como pide Sarkar (1998) para este criterio, en tanto los organismos están constituidos por ADN y proteínas. No obstante, vale la pena señalar que no hay una total coincidencia entre la jerarquía abstracta planteada y la jerarquía de los niveles de organización: el ADN y las proteínas, que están en distintos niveles de la jerarquía abstracta, se encuentran en el mismo nivel de organización de la materia, y además otros niveles de organización (célula, tejido, órgano) no se encuentran representados en la jerarquía abstracta del flujo de información. Desde nuestro punto de vista ello tiene sentido, en tanto una de las particularidades más reconocidas del reduccionismo en Biología es el interés en fundamentar la disciplina en el nivel inferior de organización.

Sin dudas, el énfasis dado al nivel molecular puede ser asociado con la búsqueda de explicaciones generalizables, válidas para organismos diversos y de diferentes especies. Este aspecto ha sido muy estudiado como propio del reduccionismo en biología, pero a nuestros fines nos interesa destacar que en el caso del reduccionismo genético molecular no todos los componentes del nivel inferior presentan el mismo estatus. En esta dirección, Crick afirma: "Es una característica esencial de mi argumento que en biología las proteínas son especialmente importantes. No deben ser clasificadas junto con los polisacáridos, por ejemplo, que en comparación juegan un papel muy menor. Sus rivales más cercanos son los ácidos nucleicos" (Crick 1958, p. 138). De esta manera, se puede ver que si bien es cierto que el nivel inferior de organización es más relevante que los otros niveles, dentro del inferior, se tiene mayor ponderación por aquellas moléculas pertenecientes al flujo de información. Los azúcares no están en la misma consideración que las proteínas y los ácidos nucleicos.

La relevancia diferencial de las entidades pertenecientes al nivel inferior de organización puede provenir de que el código genético y los procesos involucrados en el flujo de información desde el ADN hasta las proteínas presentan cierto grado de homogeneidad entre las especies. Sin dudas, ello ha dado lugar a la idea de que en su estudio se encuentran los elementos claves para entender al conjunto de los seres vivos. Al respecto, es preciso notar que en el momento de construcción del reduccionismo genético molecular, los modelos biológicos empleados son principalmente microorganismos (Neurospora, el virus T4, la bacteria E. coli) y que desde allí se ha 
pretendido dar cuenta de fenómenos biológicos de organismos eucariotas pluricelulares. De manera paradigmática, la frase de Monod "Lo que es verdad para E. coli es verdad para el elefante" (citada en Kepes 1979, p. 149) en relación a la validez "universal" de la noción de "programa genético" expone la posición reduccionista y los límites que, en ocasiones, el reduccionismo tiene y que si no son lo suficientemente considerados puede generar explicaciones espurias.

Así pues, el reduccionismo genético molecular presenta una mayor importancia del nivel inferior de organización y dentro de dicho nivel, se privilegia a aquellas entidades que conciernen al flujo de información. Esta perspectiva condice con lo propuesto anteriormente para la jerarquía abstracta, en la cual hay una primacía del primer intervalo de la jerarquía informacional (Figura 2).
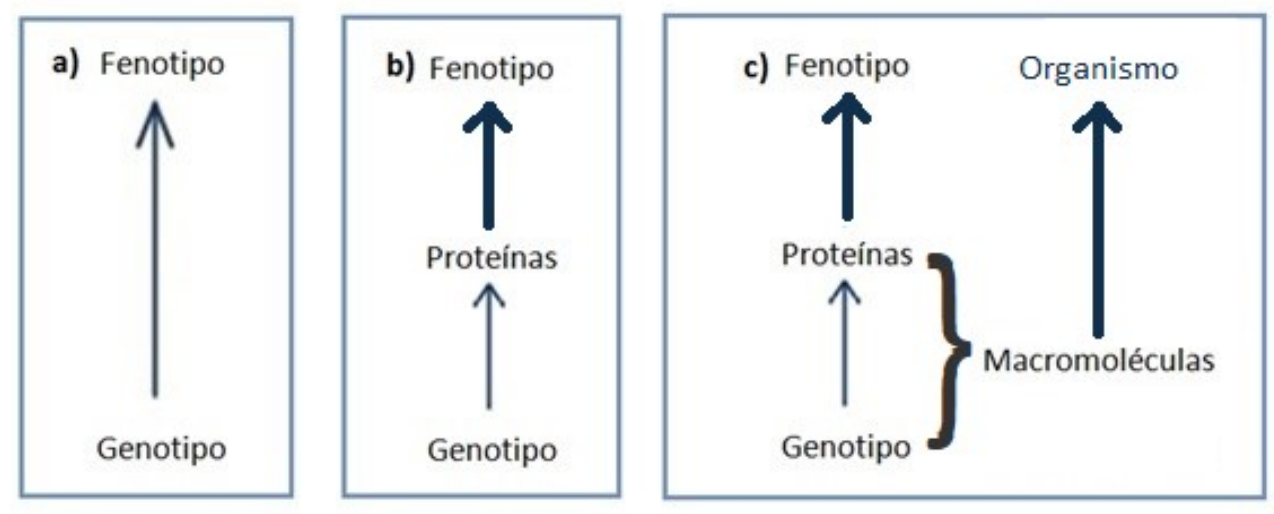

Figura 2: Criterios sustantivos de Sarkar para el caso del reduccionismo genético en los inicios de la etapa molecular. Los dominios involucrados son el genotipo y el fenotipo, siendo el primero el Dominio-F. Las flechas indican el sentido de la explicación. a) Fundamentalismo, b) Jerarquía abstracta, con sus dos intervalos, pero remarcando la subsunción del primer intervalo por sobre el segundo; c) Jerarquía Física, marcando la primacía del nivel macromolecular y de las entidades del flujo de información en tal nivel, coincidente con la mayor importancia del primer intervalo de la jerarquía abstracta.

\section{Conclusiones y comentarios finales}

La búsqueda de las características de la explicación reduccionista basada en la genética molecular ha sido el motivo de la indagación en Sarkar. Para ello, hemos recorrido los aportes del autor en relación con la problemática del reduccionismo en general, 
y a las discusiones en torno al reduccionismo genético y físico en particular. En gran medida, la distancia que el autor ha tenido de los planteos nagelianos al hacer énfasis en los "asuntos sustantivos" han hecho que su propuesta resultara muy clarificadora y conveniente por su simplicidad. Primordialmente, su consideración en que es preciso observar las representaciones que los científicos tienen del mundo en lugar de la estructura formal de las explicaciones han hecho más acertado el análisis del reduccionismo. No obstante, precisamente la búsqueda de las maneras en que los científicos representan la relación entre el genotipo y el fenotipo nos ha llevado a presentar ciertas discrepancias con la postura del autor, principalmente en relación con la necesidad de considerar una imbricación entre las perspectiva molecular y genética para analizar el estado del reduccionismo en la Biología contemporánea.

Así pues, el modelo sarkariano nos ha permitido observar cuáles son los elementos que componen las estructuras de las explicaciones reduccionistas. El primero de ellos, la consideración de que los cambios a nivel fenotípico se deben a modificaciones en el ámbito genotípico a partir de aproximar las nociones de gen clásico y molecular. Tal señalamiento permite abrir una discusión respecto a las características de las entidades bajo estudio en la disciplina biológica y las suposiciones implícitas, problemáticas en algunos casos, que pueden llegar a darse. En segundo lugar, hemos reconocido que la forma de representar la relación entre el genotipo y el fenotipo se encuentra dada por dos intervalos de flujo de información: aquel definido por Crick en el dogma central y cuya regulación han estudiado Jacob y Monod - desde los genes hasta las proteínas - y el propio desde las proteínas hasta el fenotipo, menos precisado, y visto en gran medida como simple resultado de las funciones proteicas. El último criterio del modelo sarkariano nos ha permitido señalar que las explicaciones del reduccionismo genético actual — a diferencia del propio de la genética clásica emplean entidades planteadas por teorías físicas y químicas, principalmente aquellas pertenecientes al flujo de información del nivel inferior de organización. Sin dudas, el énfasis en dichas entidades proviene de la búsqueda de explicaciones generales sostenida en el empleo de determinados modelos biológicos.

Ciertamente, los ítems señalados como propios de las explicaciones reduccionistas han sido en alguna medida rechazados por la propia comunidad biológica y filosófica. A nuestro parecer, este es un aspecto de suma importancia en tanto da muestra de que las explicaciones reduccionistas eluden elementos teóricos propios de la disciplina biológica. Algunos de ellos provienen ya desde el estudio de los organismos eucariotas en la década de los '70, en tanto la revelación de su complejidad ha mostrado varias limitaciones que los modelos biológicos empleados no permitían dilucidar. La identificación del gen clásico con el gen molecular e incluso la idea misma de "gen", la noción de programa genético con el operón lac como paradigma para dar cuenta de la embriogénesis, el dogma central tal como fue planteado originalmente son algunas de las conceptualizaciones que han sido criticadas en la Biología de los 
últimos años. Asimismo, se ha señalado como problemática a la noción de información no sólo por su significado polisémico, sino también por el rol que tal concepto ha tenido en la consolidación de la visión gen-centrista en Biología (Oyama 1985; Keller 2000; Jablonka, Lamb y Zeligowski 2013). Por su parte, en organismos pluricelulares se han desarrollado elementos teóricos propios del intervalo informacional proteínas-fenotipo - soslayado en la visión reduccionista presentada - tales como los estudios de acción hormonal (ver Morange 2000). El lenguaje empleado evoca a su vez la temática informacional: "segundos mensajeros", "transducción de señales", "receptores", "amplificación de la señal", "comunicación celular", entre otros.

Desde nuestro punto de vista, es importante admitir que el reduccionismo persiste pese a las críticas recibidas, ya que abre paso a la discusión acerca de por qué lo hace. En este sentido, es preciso indagar por qué es posible hallar numerosas investigaciones en donde la aproximación entre gen clásico y molecular resulta problemática o en las que se propone que en el $\mathrm{ADN}$ se encuentra la información suficiente para entender enfermedades complejas. Una de las posibilidades es que esta perspectiva resulta útil a fines instrumentales, cuando se busca la intervención para alterar un determinado fenotipo. Así pues, las perspectivas reduccionistas las encontramos en numerosas aplicaciones farmacéuticas y biotecnológicas, programas de investigación que buscan en la información genética las bases para descripciones fenotípicas, por ejemplo, en la perspectiva biomédica de la genómica personalizada (Pavone 2007). Las promesas y realidades de los organismos genéticamente modificados también constituyen un claro caso donde el modelo sarkariano presentado aplica correctamente.

Sin dudas, algunos puntos más deben ser observados en el futuro para un abordaje más completo del reduccionismo genético molecular. Entre ellos, el lugar del ambiente, el cual suele ser señalado en las discusiones sobre el reduccionismo como un aspecto soslayado por tales puntos de vista. El modelo de Sarkar aquí no ofrece demasiadas ventajas, aunque en el caso del reduccionismo planteado, podríamos sugerir que los aspectos contextuales son desplazados debido a la primacía epistémica otorgada al ámbito genético, posición cuyo origen se puede situar en la consolidación de la Síntesis Moderna. Asimismo, dado que observamos que las explicaciones reduccionistas son particularmente buscadas parece necesario sumar al análisis de la reducción explicativa otros elementos, por ejemplo, metodológicos.

Por último, la permanencia de las explicaciones reduccionistas ha puesto como desafío reconocer la diversidad de perspectivas hacia adentro de la propia disciplina biológica. En efecto, el modelo de reducción expuesto busca poder dilucidar los elementos que componen una visión en particular de la disciplina, y en este punto se distancia de Sarkar, en tanto él intenta dar cuenta de las características del reduccionismo en general, en toda la Biología. Seguramente la aplicación del modelo propuesto a programas de investigación vigentes nos pueda aportar más elementos 
acerca de cómo se omiten, simplifican y eluden las perspectivas críticas mencionadas.

\section{Referencias}

Brigandt, I. y Love, A. 2017. Reductionism in Biology. En: E. Zalta (ed.) The Stanford Encyclopedia of Philosophy. Standford: Standford University Press. https://plato.stanford.edu/ archives/spr2017/entries/reduction-biology Acceso: 01/09/2014.

Callebaut, W. 1995. Réduction et explication mécaniste en biologie. Revue philosophique de Louvain 93(1): 33-66.

Caponi, G. 2004. El reduccionismo en la biología contemporánea. Signos filosóficos 6(12): 33-62.

Carrier, M. y Finzer, P. 2006. Explanatory loops and the limits of genetic reductionism. International Studies in the Philosophy of Science 20(3): 267-283.

Crick, F. H. 1958. On protein synthesis. Symposia of the Society for Experimental Biology 12: 138-163.

Etxeberria Agiriano, A., y Garcia Azkonobieta, T. 2004. Sobre la noción de información genética: seméntica y excepcionalidad. Theoria. Revista de Teoría, Historia y Fundamentos de la Ciencia 19(2): 209-230.

Falk, R. 2009. Genetic Analysis, a history of genetic thinking. UK: Cambridge University Press.

Fodor, J. A. 1974. Special sciences (or: The disunity of science as a working hypothesis). Synthese 28(2): 97-115.

Gilbert, S. F. y Sarkar, S. 2000. Embracing complexity: organicism for the 21st century. Developmental dynamics: an official publication of the American Association of Anatomists 219(1): 1-9.

Godfrey-Smith, P. 2004. Genes do not encode information for phenotypic traits. En: C. Hitchcock (ed.), Contemporary debates in philosophy of science, p.275-289. USA: Blackwell Publishing.

Godfrey-Smith, P. y Sterelny, K. Biological Information. En: E. Zalta. (ed.) The Stanford Encyclopedia of Philosophy. Standford: Standford University Press. https://plato.stanford.edu/ archives/sum2016/entries/information-biological Acceso: 01/09/2019.

Griffiths, P. E. 2001. Genetic information: A metaphor in search of a theory. Philosophy of Science 68(3): 394-412.

Hull, D. L. 1972. Reduction in genetics--biology or philosophy? Philosophy of Science 39(4), 491-499.

Jablonka, E.; Lamb, M. J. y Zeligowski, A. 2013. Evolución en cuatro dimensiones: genética, epigenética, comportamientos y variación simbólica en la historia de la vida. Buenos Aires: Capital Intelectual.

Jacob, F. y Monod, J. 1961. Genetic regulatory mechanisms in the synthesis of proteins. Journal of molecular biology 3(3): 318-356.

Kaiser, M. I. 2012. Why It Is Time to Move Beyond Nagelian Reduction. In: Probabilities, laws, and structures. Dordretch: Springer, 245-262.

Kaiser, M. I. 2015. Reductive explanation in the biological sciences. Cham: Springer International Publishing. 
Keller, E. F. 1990. Physics and the Emergence of Molecular Biology: A History of Cognitive and Political Synergy. Journal of the History of Biology 23(3): 389-409.

Keller, E. F. 2000. The century of the gene. United States: Harvard University Press.

Kepes, A. 1979. Early Kinetics of Induced Enzyme Synthesis. En: A. Lwoff y A. Ullmann. Origins of molecular biology: a tribute to Jacques Monod, p. 149-156. London: Academic Press, Inc.

Klimovsky, G. 1997. Las desventuras del conocimiento científico. 3a ed. Buenos Aires: A-Z editora.

Krimsky, S. y Gruber, J. 2013. Genetic explanations: sense and nonsense. Harvard: Harvard University Press.

Mahner, M. 2001. Genetics and reductionism: Unveiling mechanisms without metaphysics? Biology and Philosophy 16(3): 395-403.

Martin C. y Finzer, P. 2006. Explanatory Loops and the Limits of Genetic Reductionism. International Studies in the Philosophy of Science 20(3), 267-283.

Mayr, E. 1988. Toward a new philosophy of biology: observations of an evolutionist. Cambridge: Harvard University Press.

McLaughlin, B. y Bennett, K. 2018. Supervenience. En: E. Zalta (ed.) The Stanford Encyclopedia of Philosophy. Standford: Standford University Press. https://plato.stanford.edu/ archives/win2018/entries/supervenience Acceso: 01/09/2010.

Morange, M. 2000. Gene function. Comptes Rendus de l'Académie des Sciences-Series III-Sciences de la Vie 323(12): 1147-1153.

Moss, L. 2003. What genes can't do. USA: MIT Press.

Nagel, E. 1961. The structure of science: Problems in the logic of scientific explanation. USA: Harcourt, Brace \& World, Inc.

Noble, D. 2006. The music of life: biology beyond genes. Oxford: Oxford University Press.

Pavone, V. 2007. Biotecnologías y cambio social: ¿derecho a la salud o derecho a estar sanos?: Ingeniería genética, biomedicalización y elección individual. Administración \& cidadanía: revista da Escola Galega de Administración Pública 2(1): 77-92.

Rose, S; Lewontin, R.C. y Kamin, L. J. 1984. Not in our genes. England: Penguin Books.

Rosenberg, A. 1985. The structure of biological science. Cambridge, USA: Cambridge University Press.

Rosemberg, A. 2006. Darwinian reductionism: or, how to stop worrying and love molecular biology. Chicago: University of Chicago Press.

Sarkar, S. 1992. Models of reduction and categories of reductionism. Synthese 91(3): 167194.

Sarkar, S. 1996. Decodingçoding": Information and DNA. BioScience 46(11): 857-864.

Sarkar, S. 1998. Genetics and reductionism. Cambridge, USA: Cambridge University Press.

Sarkar, S. 2002. How to, and how not to, be a reductionist. En: M.H.V. Van Regenmortel y D.L. Hull (ed.) Promises and limits of reductionisms in the biomedical sciences, p.191-209. Sussex, England: John Wiley \& Sons Ltd.

Sarkar, S. 2004. Genes encode information for phenotypic traits. En: C. Hitchcock, Contemporary debates in philosophy of science, p.259-274. USA: Blackwell Publishing.

Sarkar, S. 2005. Molecular models of life: philosophical papers on molecular biology. Cambridge, USA: Cambridge University Press. 
Stotz, K., Griffiths, P. E. y Knight, R. 2004. How biologists conceptualize genes: an empirical study. Studies in History and Philosophy of Science Part C: Studies in History and Philosophy of Biological and Biomedical Sciences 35(4): 647-673.

Tauber, A. I. y Sahotra S. 1992. The human genome project: has blind reductionism gone too far? Perspectives in biology and medicine 35(2): 220-235.

Tauber, A. I.; Sarkar, S. 1993. The ideology of the human genome project. Journal of the Royal Society of Medicine, 86(9), 537-540.

Van Riel, R. y Van Gulick, R. 2018. Scientific Reduction. En: Zalta, E. (ed.) The Stanford Encyclopedia of Philosophy. Standford: Standford University Press. https://plato.stanford. edu/archives/sum2018/entries/scientific-reduction Acceso: 01/09/2019.

Waters, C. K. 1994. Genes made molecular. Philosophy of Science 61(2): 163-185.

Wimsatt, W. 2006. Reductionism and its heuristics: Making methodological reductionism honest. Synthese 151(3): 445-475.

Wimsatt, W.; Sarkar, S. 2006. Reductionism. En: S. Sarkar, y J. Pfeifer (eds.), The philosophy of science: an enciclopedia, p.696-703. New York: Routledge.

\section{Notas}

${ }^{1}$ Sarkar emplea un argumento histórico: en la primera mitad del siglo XX, los trabajos del físico Max Delbruck en el conocido "grupo de los fagos" implicaron una metodología reduccionista y la explicación resultante no lo fue (ver Sarkar 1992, 1998).

${ }^{2}$ Esto no significa que se eliminen las perspectivas moleculares y clásicas. Para los casos mencionados también puede haber explicaciones con el concepto molecular de gen o el gen clásico, pero éstas no cumplirían el criterio fundamentalista tal como está planteado aquí. 